\title{
The Tensile Properties and Fracture Behavior of Two High Strength Steels: Influence of Coating
}

\author{
Paul Arindam ${ }^{1}$, T. S. Srivatsan ${ }^{1 *}$, G. L. Doll ${ }^{2,3}$ \\ ${ }^{1}$ Division of Materials Science and Engineering, Department of Mechanical Engineering, University of Akron \\ ${ }^{2}$ Timken Engineered Surfaces Laboratory, Akron Engineering Research Center, University of Akron \\ ${ }^{3}$ Department of Civil Engineering, University of Akron
}

Received: March 11, 2016; Accepted: April 05, 2016; Published: April 25, 2016

*Corresponding author: T. S. Srivatsan, Division of Materials Science and Engineering, Department of Mechanical Engineering, Akron, Ohio 44325-3903, USA.E-mail: srivatsants@yahoo.com

\begin{abstract}
Chromium nitrate is a preferred coating that has been preferentially chosen and extensively used for purpose of improving the corrosion resistance of metals when exposed to environments spanning a range of aggressiveness. In this paper, the results of a study in which chromium nitrate was used as a surface coating on two widely chosen and used high strength steels is presented and discussed. The steels chosen were 17-4 PH stainless steel and the high strength alloy steel (300M). Results reveal the coating to have a beneficial influence on both yield strength and tensile strength of the chosen 17-4 PH stainless steel. For the high strength alloy steel $300 \mathrm{M}$, the coating was observed to have a positive influence on both yield strength and tensile strength with a noticeable reduction in ductility. The kinetics of the presence of coating on tensile fracture behavior is highlighted in light of intrinsic microstructural effects, deformation characteristics of the microstructural constituents and nature of loading.
\end{abstract}

Keywords: Coating; Stainless steel; Alloy steel; Tensile response; Fracture behavior

\section{Introduction}

A growing interest in the use of protective coatings on the surface of a metal has been shown to be an economically affordable and potentially viable alternative for a number of purposes to include the following: (a) improving and/or enhancing the mechanical properties of the chosen metal, (b) improving resistance to environment induced degradation or corrosion, and (c) improved resistance to wear [1]. Over the years, few to several methods have been developed and put forth in an attempt to accomplish protective coatings on a structural metal. A few of these include the following: (i) Electrode position, (ii) Physical vapor deposition (PVD), (iii) Chemical vapor deposition (CVD), and (iv) Thermal spraying. A few of these methods are carried out at an elevated temperature, which does tend to exert an observable influence on mechanical properties of the chosen metal [2].

Chromium Nitrate coatings are preferentially chosen and used as a viable, effective and affordable option for protecting the base material or substrate from wear and the deleterious influence of the environment often resulting in environmentdegradation or corrosion [3]. In one independent study, it was found to have or exert noticeable improvement in toughness with minimum to no improvement in other mechanical properties of interest to the engineer [4]. In a more recent study by S.Herenu and co-workers [5], on the presence and role of chromium nitrate precipitates on strain-controlled low cycle fatigue behavior of a duplex stainless steel it was found to exert a detrimental influence on low cycle fatigue properties. Furthermore, thermal treatment at an elevated temperature followed by cooling in ambient air was found to reduce the influence of the presence of chromium nitrate precipitates on the steels chosen and studied in this independent research study [5].

Stainless steel has gained for itself the advantage of being categorized as an attractive and preferred choice as an implant material for use in internal fixation. This arises primarily because of its cost effectiveness, good mechanical strength coupled with the intrinsic capability of adjusting the implant in order to obtain a custom fit [6]. In a recent study conducted by Monika Cieslika and co-workers [7] on a comparison between Parylene N coating and Parylene C coating on 316L stainless steel it was found that both micro-hardness and Young's Modulus were nearly the same within limits of experimental error for the two coatings. Furthermore, they found and documented the Parylene $\mathrm{C}$ coating to be a more suitable than Parylene $\mathrm{N}$ coating on stainless steel implant surfaces [7]. In fact a careful and comprehensive study of the experimental data collected in this research article did reveal the critical load / total delamination and coating thickness of the Parylene $\mathrm{C}$ coating to be noticeably higher when compared to the Parylene N coating. This factor contributed to the initiation of fine microscopic cracks under the influence of low applied load when the substrate is coated with Parylene N. Furthermore, the crystalline nature of Parylene N coating makes it behave more like a ceramic material than a polymeric material. The elastic nature of Parylene $\mathrm{C}$ coating makes it easier to both undergo and withstand deformation, which was observed in this study [7]. 
The mechanical properties and microstructure of AISI 4340 high strength alloy steel was investigated by Wei-Shyan Leeand co-workers [8] under various conditions of tempering. Results revealed hardness, strength, and strain-hardening exponent to noticeably decrease with an increase in both tempering temperature and hold time. Ductility, quantified by both reduction in cross-section area and elongation to failure, increased with an increase in tempering temperature and hold time. An exhaustive analysis of the fracture surfaces of the deformed and failed specimens revealed features reminiscent of "locally" ductile failure with the formation and presence of voids of varying size and dimples. They also showed that at a test temperature of $300^{\circ} \mathrm{C}$ the material experienced brittle fracture mechanism as a consequence of embrittlement of the tempered martensite [8].

The primary objective of this experimental investigation was to provide both a scientific and engineering insight into the influence of a coating on tensile response, rationalized both by way of properties and fracture behavior, of two high strength steels spanning the sub-families of stainless steel and alloy steel. The tensile fracture behavior is discussed in light of mutually interactive influences of nature of loading and intrinsic microstructural effects.

\section{Materials}

The two materials chosen for this experimental study belong to the ferrous family of alloys. The nominal chemical composition of the two high strength steels is provided in Table 1 . In the case of both alloy steel [300M] and stainless steel [17-4PH] the presence of carbon in the composition provides solid solution strengthening while concurrently enabling in a noticeable enhancement in hardenability through the formation and presence of alloy carbides in the microstructure. The presence of the alloying elements chromium (Cr), nickel (Ni), molybdenum (Mo) and manganese (Mn) aids in the formation and presence of carbide particles dispersed through the microstructure thereby contributing in a small way to increasing the strength of the steel matrix.

The two chosen high strength steels were coated using a cathodic arc deposition technique, which is categorized to be one of the most widely used physical vapor deposition [PVD] techniques. The process was conducted by striking high current using a low voltage arc on the surface of the substrate. This often necessitates the need for high local temperature, which serves to successfully vaporize the coating material upon application. Subsequently, this condenses on to the substrate forming a thin layer.

\section{Experimental Procedures}

The tensile tests were performed on the two chosen high strength steels, i.e., 17-4 PH stainless steel and 300M alloy steel.

\section{Test sample preparation}

Cylindrical test specimens were precision machined from the blanks on a CNC machine and conformed to specifications outlined in standard ASTM E-8 [8]. The threaded specimen measured 58.4
Table 1: Nominal chemical composition of the two steels chosen, i.e., 17-4 PH stainless steel, and 300M alloy steel.

\begin{tabular}{|l|c|l|c|}
\hline \multicolumn{2}{|c|}{ 17-4 PH stainless steel } & \multicolumn{2}{c|}{ 300M alloy steel } \\
\hline \multicolumn{1}{|c|}{ Elements } & $\begin{array}{c}\text { Weight Percentage } \\
(\%)\end{array}$ & \multicolumn{1}{|c|}{ Elements } & $\begin{array}{c}\text { Weight } \\
\text { Percentage (\%) }\end{array}$ \\
\hline Carbon & 0.07 max & Carbon & 0.45 \\
Manganese & $1.00 \mathrm{max}$ & Copper & 0.35 \\
Phosphorus & $0.04 \mathrm{max}$ & Silicon & 1.8 \\
Sulphur & $0.03 \mathrm{max}$ & Manganese & 0.9 \\
Silicon & $1.00 \mathrm{max}$ & Phosphorus & 0.01 \\
Chromium & $15.00-17.50$ & Sulphur & 0.01 \\
Nickel & $3.00-5.00$ & Sulphur + & 0.025 \\
Copper & $3.00-5.00$ & Phosphorus & \\
Iron & Rest & Chromium & 0.95 \\
& & Molybdenum & 0.5 \\
& & Nickel & 2 \\
& & Vanadium & 0.10 \\
\hline
\end{tabular}

$\mathrm{mm}$ in length and $12.70 \mathrm{~mm}$ in diameter at the thread region. The gage length of the finished or machined specimen measured $12.70 \mathrm{~mm}$ in length and $3.175 \mathrm{~mm}$ in diameter. To minimize the extrinsic influence of surface irregularities and surface finish, and considering the importance of surface finish to ensure adherence of the coating, abundance of care and caution were taken during: (i) handling of the test specimens both prior to and during the coating , (ii) handling following coating, and (iii) handling during testing on a servo-hydraulic test machine. Blanks of the 17-4 PH stainless steel were machined along the longitudinal (L) direction of the as-provided stock. Blanks of alloy steel 300M were machined from both the longitudinal $(\mathrm{L})$ and transverse $(\mathrm{T})$ directions of the as-provided plate stock. A schematic of the test specimen used is shown in Figure 1.

\section{Initial microstructure characterization}

Initial microstructural evaluation of the as provided materials was done using a low magnification optical microscope. Samples of desired shape and size were cut from the two high strength steels and mounted in epoxy. The steel samples embedded in epoxy were then mechanically ground on progressively finer grades of silicon carbide impregnated emery paper using copious amounts of water as lubricant. The mechanically ground and rough polished samples were then fine polished using one-



Figure 1: A schematic of the cylindrical test specimen used for the mechanical tests. All Dimensions are in $\mathrm{mm}$. 
micron alumina suspended in distilled water as the lubricant. The finish polished samples had a near mirror-like surface finish. The round and polished samples of the three chosen alloys were then etched as follows:

(a) The 17-4 PH stainless steel sample was etched using Fry's reagent; a solution mixture of $30 \mathrm{ml} \mathrm{H}_{2} \mathrm{O}, 40 \mathrm{ml} \mathrm{HCL}, 25 \mathrm{ml}$ ethanol and $5 \mathrm{~g} \mathrm{CuCl}_{2}$;

(b) Alloy steel $300 \mathrm{M}$ was etched using a solution mixture of $10 \mathrm{ml}$ of nitric acid $\left(\mathrm{HNO}_{3}\right)$ and $90 \mathrm{ml}$ of ethanol, also known as 'Nital' reagent.

(c) The etched samples were observed in a low magnification optical microscope using bright field illumination technique.

\section{Mechanical testing}

Uniaxial tensile tests were performed up until failure on a fully automated, closed-loop servo-hydraulic mechanical test machine (INSTRON: Model 8500 Plus) equipped with a $25 \mathrm{KN}$ load-cell. The test specimens of the three chosen materials were deformed at a constant strain rate of $0.0001 / \mathrm{sec}$. An axial 12.5 $\mathrm{mm}$ gage length clip-on extensometer was attached to the test specimen using rubber bands to provide a measure of strain during uniaxial stretching. The stress and strain measurements, parallel to the load line, were recorded on a PC-based data acquisition system (DAS).

\section{Failure-Damage analysis}

Fracture surface of the fully deformed and failed samples were carefully examined in a Scanning Electron Microscope (SEM) to determine the macroscopic fracture mode and to also help characterize the fine scale features on the tensile fracture surface that would help establish the fine microscopic mechanisms governing tensile fracture. In this study, the macroscopic mode refers to the overall mode of failure, while the microscopic mechanisms includes all of the failure processes occurring at the 'local' level, such as, (a) microscopic void formation, (b) microscopic void growth, (c) their eventual coalescence to form one or more fine microscopic cracks, and (d) the nature, extent and severity of macroscopic cracking.

\section{Results and Discussion}

\section{Initial microstructure}

The study of initial microstructure is very important to analyze tensile properties, fracture behavior, fracture toughness and resultant fracture behavior. The optical micrographs of 17-4 PH stainless steel and 300M alloy steel are shown in Figure 2 and Figure 3 respectively.

Optical micrographs of 17-4 PH stainless steel are shown in Figure 2, which is taken at two different magnifications. The micrographs reveal a dual phase microstructure comprising of irregular portions or patches of light color regions or ferrite (pure iron) and a random distribution of dark color regions, of varying size, or martensite (the carbon-rich micro constituent). The martensite present had a near needle-like morphology of varying size and thickness.

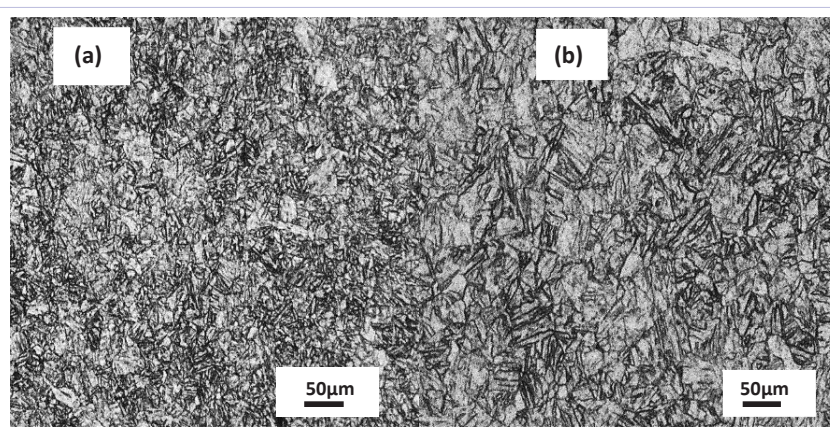

Figure 2: Optical micrographs of 17-4 $\mathrm{PH}$ precipitation hardenable stainless steel showing:

a) Low magnification showing a mixture of ferrite and martensite.

b) High magnification observation of (a) showing the morphology and distribution of the two key micro-constituents ferrite and martensite

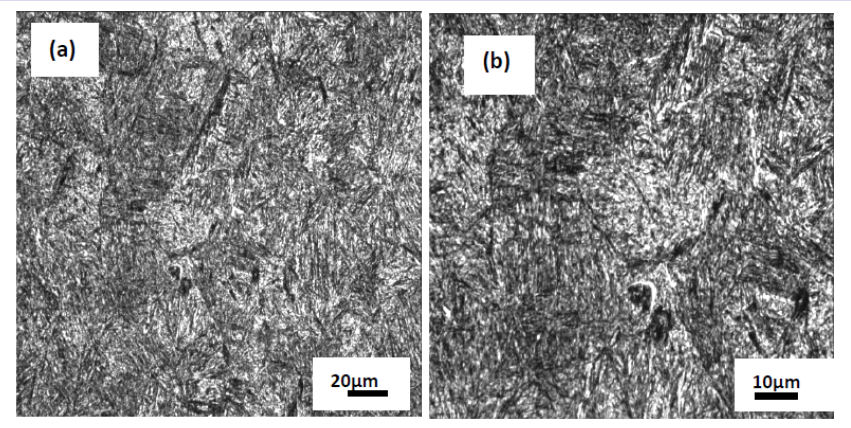

Figure 3: Optical micrographs showing key micro-constituents in alloy steel $300 \mathrm{M}$ at two different magnifications.

The micrographs of high strength alloy steel 300M are shown in Figure 3 and reveal a combination of carbon-rich and carbondepleted region. A higher carbon and alloy content in this alloy steel resulted in a greater volume fraction of martensite in the carbon-rich regions. The martensite, in the form of needles, was much finer and intermingled with random pockets of the ferrite-rich region. The presence of martensite micro-constituent in the carbon-rich regions is governed by a synergism of both composition and primary processing used to engineer the alloy stock. This does exert an influence on mechanical properties of the as provided plate.

\section{Tensile properties}

The uniaxial tensile properties of the two chosen high strength steels are summarized in Table 2. Results reported are the mean values based on duplicate tests conducted on each material. In Table 2 we provided the tensile properties of the untreated samples of the two chosen high strength steels. Also provided in this table is a compilation of tensile properties of the samples that were coated with chromium nitrate.

(A) (i) For the 17-4 PH stainless steel the value of elastic modulus was $227 \mathrm{GPa}$ for the Untreated sample and for the coated samples. The elastic modulus was $220 \mathrm{GPa}$, a minimal difference well within the limits of experimental error. 
Table 2: A compilation of the elastic modulus, yield strength, ultimate strength, and elongation measured on untreated and coated samples of 17-4 PH stainless steel and 300M alloy steel [both Longitudinal (L) and Transverse (T) orientations].

\begin{tabular}{|l|l|l|l|l|}
\hline Untreated samples & $\begin{array}{l}\text { Elastic Modulus } \\
\text { (GPa) }\end{array}$ & $\begin{array}{l}\text { Yield Strength } \\
\text { (MPa) }\end{array}$ & $\begin{array}{l}\text { Ultimate strength } \\
\text { (MPa) }\end{array}$ & $\begin{array}{l}\text { Elongation } \\
(\%)\end{array}$ \\
\hline 17-4 PH Stainless Steel & 227 & 1027 & 1140 & 11 \\
\hline 300M Alloy Steel (Longitudinal) & 233 & 505 & 914 & 16 \\
\hline 300M Alloy Steel (Transverse) & 197 & 474 & 880 & 16 \\
\hline Samples Coated with Chromium Nitrate & 220 & 1177 & 1179 & 11 \\
\hline 17-4 PH Stainless Steel & 435 & 836 & 14 \\
\hline 300M Alloy Steel (Longitudinal) & 248 & 436 & 843 & 15 \\
\hline 300M Alloy Steel (Transverse) & 208 & & & \\
\hline
\end{tabular}

(ii) Alloy steel 300M was tested in both the longitudinal and transverse directions. For sample taken from the longitudinal orientation the elastic modulus was $248 \mathrm{GPa}$ for the coated sample, and for the untreated sample the elastic modulus was marginally lower than the coated sample and $233 \mathrm{GPa}$. Sample of this alloy taken from the transverse orientation the elastic modulus was $+197 \mathrm{GPa}$ for the untreated sample and as high as $208 \mathrm{GPa}$ for the coated counterpart.

(B) (i) Untreated sample of 17-4 PH stainless steel had yield strength of $1027 \mathrm{MPa}$ while a yield strength of $1177 \mathrm{MPa}$ was recorded for the coated sample, which is the highest value of yield strength achieved among the two chosen metals.

(ii) For high strength alloy steel 300M samples from both the longitudinal and transverse orientation revealed a marginally lower value of yield strength for the coated samples when compared one-one with the untreated counterpart. The yield strength strength of the coated sample was $435 \mathrm{MPa}$ for the longitudinal (L) orientation and $436 \mathrm{MPa}$ for the transverse (T) orientation. Untreated sample of alloy steel $300 \mathrm{M}$ was found to have yield strength of $505 \mathrm{MPa}$ for the test sample taken from the longitudinal (L) orientation while sample taken from the transverse (T) orientation had a yield strength of $474 \mathrm{MPa}$.

(C) (i) The 17-4 PH stainless steel was found to reveal a marginal increment in UTS when the test sample coated with chromium nitrate was deformed in uniaxial tension. The UTS for the untreated sample was $1140 \mathrm{MPa}$ while strength was as high as $1179 \mathrm{MPa}$ for the coated counterpart.

(ii) For alloy steel $300 \mathrm{M}$ coating was found to have a marginal detrimental influence on tensile strength. For the longitudinal (L) orientation the value of tensile strength decreased from $914 \mathrm{MPa}$ (untreated) to $836 \mathrm{MPa}$ (coated). However, sample prepared from the transverse (T) orientation the UTS was $880 \mathrm{MPa}$ for the untreated sample and only $843 \mathrm{MPa}$ for the coated counterpart.

(D)(i) Alloy steel $300 \mathrm{M}$ tends to follow the same pattern for both the longitudinal and transverse orientations of the test samples. For the longitudinal (L) orientation the value decreased by almost $2 \%$ when the coated sample is compared with the uncoated counterpart. For the transverse orientation sample the value decreased marginally by $1 \%$.
(E)(ii) The 17-4 PH stainless steel revealed both increased yield strength and ultimate tensile strength when subject to a protective coating of chromium nitrate but difficulty was found to decrease by as much as $3 \%$.

\section{Tensile fracture behavior}

An examination of the fracture surfaces over a range of allowable magnifications of the Scanning electron microscope (SEM) does provide useful information pertaining to the role and contribution of intrinsic microstructural effects on strength and ductility properties of the two chosen high strength steels. An exhaustive examination of the tensile fracture surfaces did reveal observable differences in the following: (a) macroscopic or overall fracture morphology, and (b) microscopic features and resultant mechanisms on the fracture surface. Representative fracture features of the two chosen steels are shown in Figure 4 to Figure 7.

\section{Tensile fracture of 17-4 PH stainless steel}

Scanning electron micrographs of the tensile fracture surface of the untreated sample of 17-4 PH stainless steel shown in Figure 4 reveals a cup and cone morphology Figure 4A, which is reminiscent of globally ductile failure. High magnification observation of the fracture surface revealed dimples and an observable population of voids covering the fracture surface Figure 4B. Locally brittle and ductile failure mechanisms were easily observed due to the presence of both macroscopic cracks and a healthy population of voids and dimples Figure $4 \mathrm{C}$ and Figure 4D. Both macroscopic cracks and a sizeable population of voids, of varying size, were seen covering the overload fracture surface. SEM's of the coated sample of 17-4 PH stainless steel are shown in Figure 5 and reveal an overall cup and cone morphology of failure Figure 5A. High magnification observation revealed a sizeable number or population of dimples of varying size Figure 5B. The nature, morphology and distribution of dimples on the overload fracture surface are shown in Figure 5c. Also observed on the fracture surface was a distinct distribution of both macroscopic and fine microscopic voids along with void coalescence to form fine microscopic cracks as a consequence of void growth during far field tensile loading Figure 5D. 

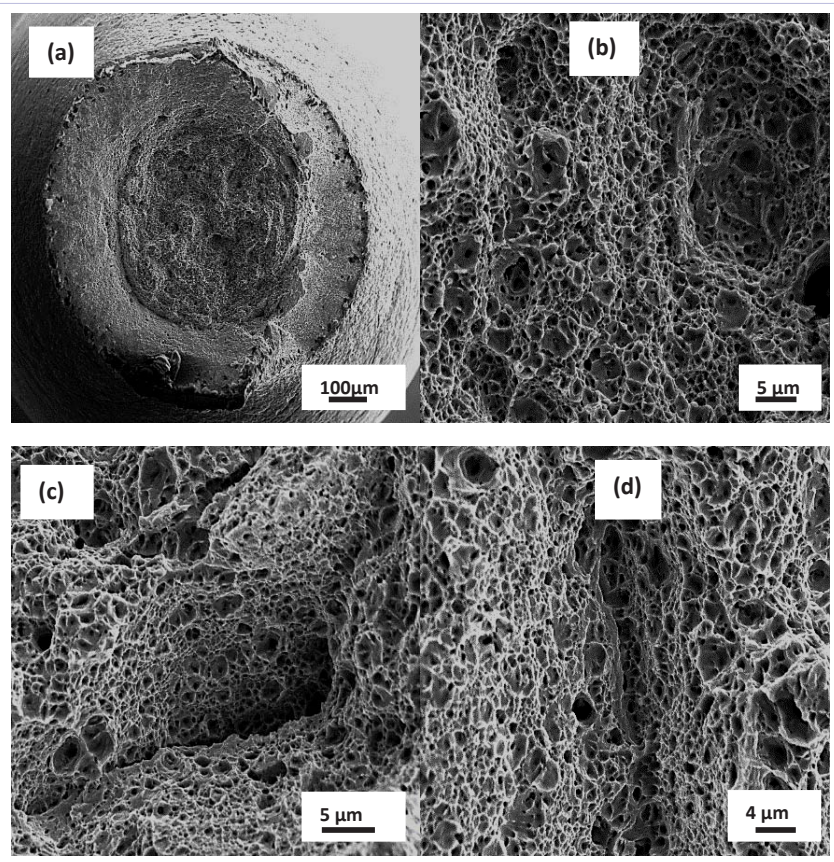

Figure 4: Scanning electron micrograph of the fracture surface features of 17-4 PH stainless steel that was deformed in uniaxial tension, showing:

(a) Overall morphology of failure

(b) High magnification observation of (a) showing dimples and voids covering the fracture surface

(c) Macroscopic cracks intermingled with a healthy population of voids and dimples reminiscent of locally brittle and ductile failure mechanisms

(d) Cracks, voids of varying size and dimples covering the overload fracture surface.
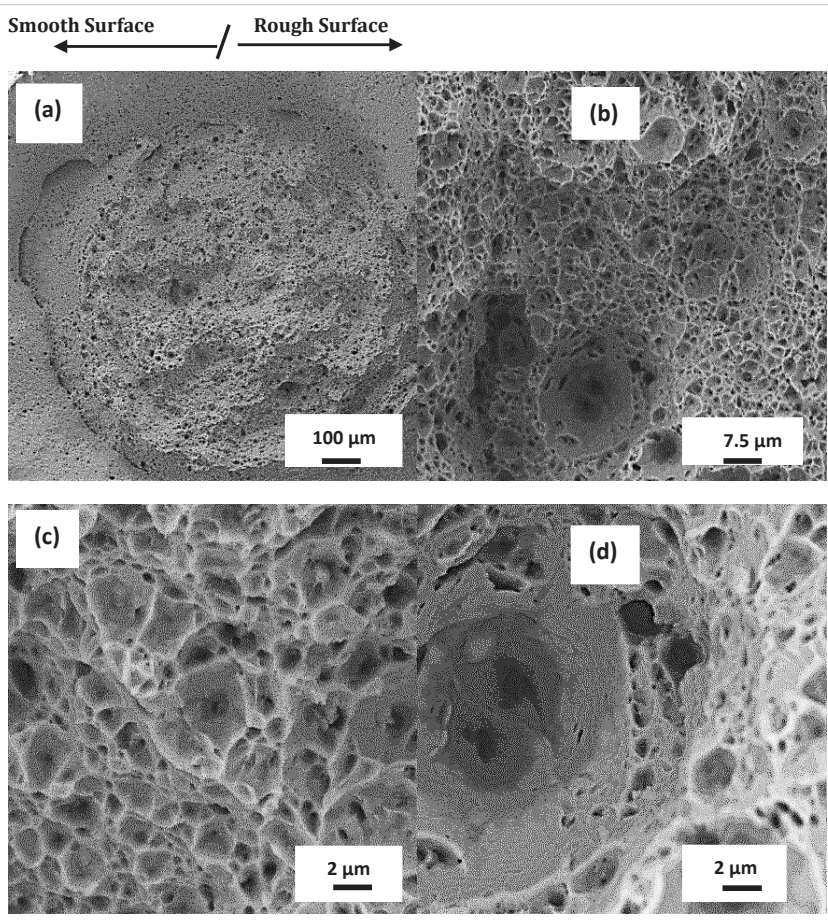

Figure 5: Scanning electron micrographs of the 17-4 Precipitation hardened stainless steel that was coated with chromium nitrate, showing:

(a) Overall morphology of failure

(b) High magnification observation of (a) showing dimples of varying size and a noticeable number of dimples.

(c) The nature, morphology and distribution of dimples on the overload fracture surface.

(d) Distribution of microscopic and fine macroscopic voids and void coalescence 

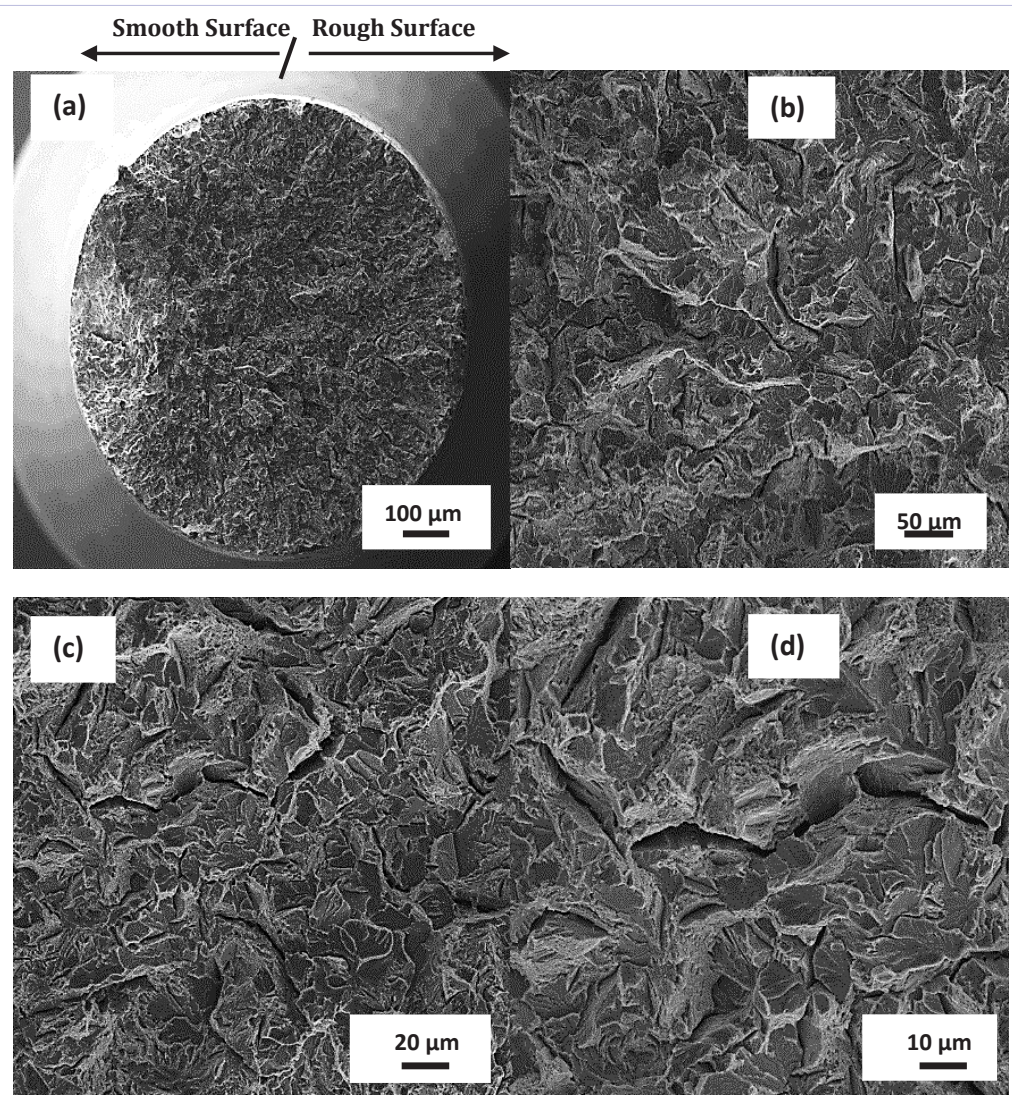

Figure 6: Scanning electron micrographs of alloy steel 300M taken from the longitudinal orientation that was coated with chromium nitrate, and deformed in tension, showing:

(a) Overall morphology of failure normal to the far- field stress axis.

(b) High magnification observation of the transgranular region reveals microscopically rough fracture surface.

(c) Macroscopic cracks intermingled with fine microscopic cracks in the region immediately prior to overload

(d) High magnification observation of (c) showing non-linear nature of macroscopic crack intermingled with pockets of cleavage-like faceted features reminiscent of locally acting brittle failure mechanisms

\section{Tensile fracture of $300 \mathrm{M}$ alloy steel}

Scanning electron microscopy observation of the tensile fracture surface of the coated $300 \mathrm{M}$ alloy steel sample taken from the longitudinal stock is shown in Figure 6. Overall, from a global perspective failure occurred normal to the far-field stress axis Figure 6A. High magnification observation of the transgranular regions revealed microscopically rough fracture surface Figure $6 \mathrm{~B}$. Both macroscopic and fine microscopic cracks were observed in the region immediacy prior to overload Figure 6C. The nonlinear nature of microscopic cracks intermingled with pockets of cleavage-like faceted features are reminiscent of" locally" brittle fracture mechanism occurring in the region of overload Figure 6D.

Scanning electron micrographs of the sample coated with chromium nitrate and taken from the transverse stock is shown in Figure 7. Overall morphology of failure was essentially flat and normal to the far field stress axis Figure 7A. High magnification observation at the permissible allowable magnifications of the SEM revealed a microscopically rough fracture surface Figure 7B. The nature and morphology of the key microscopic features covering the fracture surface immediately prior to overload is shown in Figure 7C. In the region of overload well distributed pockets of faceted-like features reminiscent of "locally" operating brittle failure mechanism was clearly evident Figure 7D.

\section{Load-Stress-Microstructure Interactions Governing Tensile Fracture}

For both the coated and uncoated test specimens of the two chosen high strength steels during far field loading in uniaxial tension the presence of dislocations in the microstructure of the deforming steel coupled with its gradual build up both at the grain boundaries and at the coarse second-phase particles present and distributed randomly through the microstructure does assist in the early initiation of fine microscopic voids at both the coarse and intermediate-size second-phase particles distributed through the microstructure. This is particularly favored to occur when the local strain build-up at a particle-matrix interface reaches a critical value. Initiation of a void at a coarse or intermediate size second-phase particle occurs immediately following yielding and at low values of plastic strain. During far-field tensile deformation a few of the particles are easily favored to crack on account of 


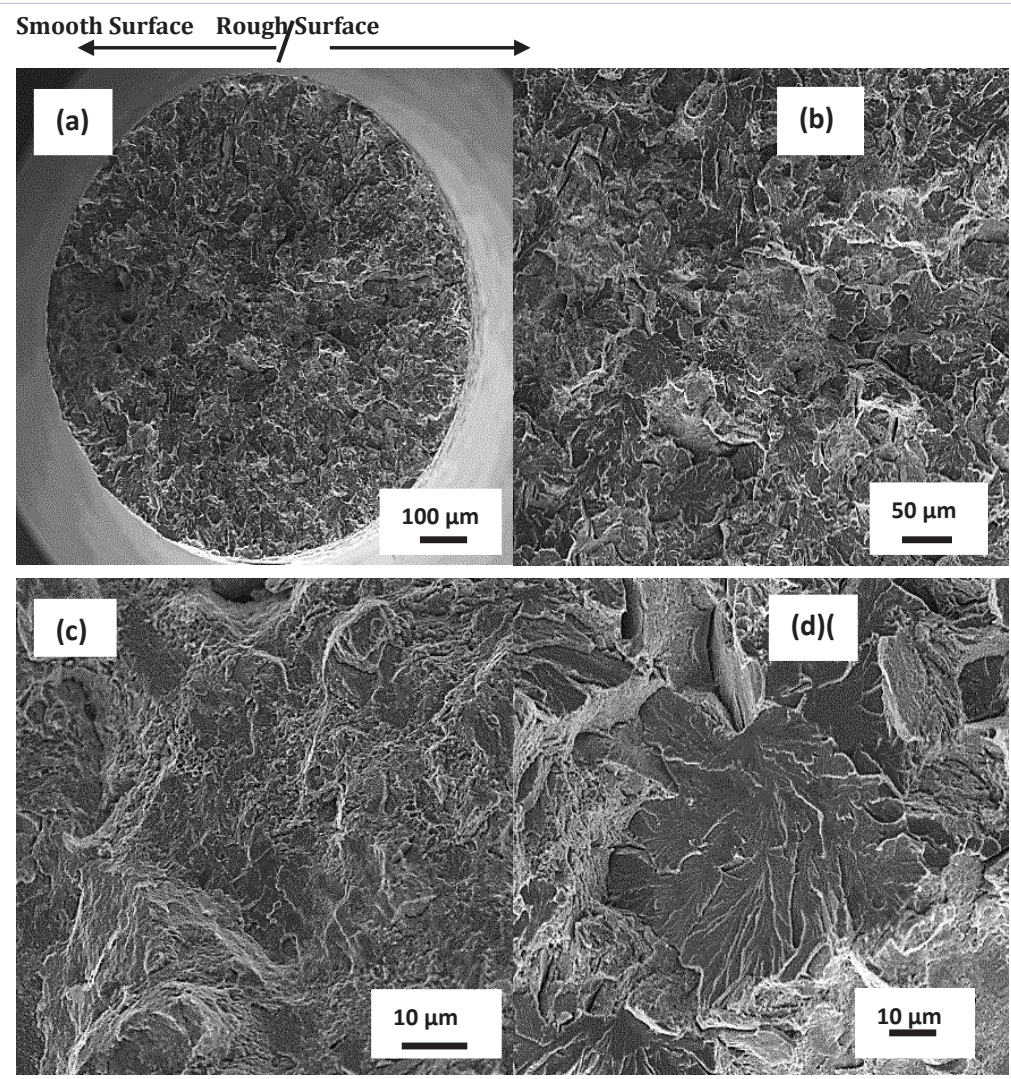

Figure 7: Scanning electron micrographs of the tensile fracture surface of chromium nitrate coated alloy steel 300M taken from the transverse orientation, showing:

(a) Overall magnification of failure, normal to the far field stress axis.

(b) High magnification observation of (a) showing microscopically rough fracture surface.

(c) High magnification observation of (b) showing the key features on the fracture surface immediately prior to overload.

(d) Well distributed pockets of faceted-like features through the fracture surface.

their intrinsic brittleness [11,12]. Since crack extension under conditions of quasi-static or tensile loading often occurs at very high 'local' stress intensities, comparable with the fracture toughness of the material, the presence of a population of both macroscopic and fine microscopic voids actually contributes to degrading the actual strain to failure [12-14].

Irrespective of the presence of a coating the formation and presence of a sizeable population of voids of varying size essentially transforms the deforming high strength steel into a composite material at the very fine microscopic level. At this level, in essence we have two populations of particles, (a) the grains in the metal matrix, and (b) voids (void now being considered as a particle having zero stiffness). Since the voids can be safely considered to be intrinsically softer than the hardened grains in the matrix, the local strain is elevated both at and around the region of a microscopic void enabling in 'local' conditions that facilitate an increase in their volume fraction. During continued loading in the tensile stress direction the fine microscopic voids gradually elongate. The elongated voids grow and eventually coalesce resulting in the formation of fine microscopic cracks for both the coated and uncoated counterparts of the two chosen steels.

\section{Conclusions}

A study aimed at understanding the influence of coating on the tensile response and fracture behavior of two high strength steels belonging to the subfamilies of stainless steel and alloy steel, provides the following key findings:

\section{Microstructure}

(i) The two ferrous alloys, i.e., stainless steel and high strength alloy steel, revealed a dual phase microstructure comprising of carbon-rich and carbon-depleted (ferrite) regions. A higher carbon and alloy content in these two chosen steels resulted in a greater volume fraction of the micro-constituent martensite in the carbon rich regions.

(ii) The presence and overall morphology of martensite in these two steels was in the form of needles of varying size and shape or thickness.

\section{Tensile Properties}

(i) Presence of coating was found to be beneficial by way of observable improvement in both yield strength and ultimate 
tensile strength of 17-4PH stainless steel. Coating was observed to have minimal influence on elastic modulus and no influence on ductility, i.e., elongation.

(ii) Presence of coating was observed to be detrimental to yield strength and ultimate tensile strength of alloy steel $300 \mathrm{M}$ in both the longitudinal (L) and transverse (T) orientations. However, presence of coating did enable in a minimum increase in stiffness or elastic modulus of this alloy steel, with no observable influence on ductility. Overall, coating was found to have marginal influence on short-term mechanical properties of the two chosen high strength steels quantified by means of a tension test.

\section{Tensile Fracture}

(i) For the two steels chosen, i.e., stainless steel and alloy steel, both the coated and untreated samples when deformed in uniaxial tension revealed a globally ductile failure and at the fine microscopic level features reminiscent of 'locally' ductile and brittle failure mechanisms.

(ii) For each chosen steel, the features were essentially the same, at the allowable magnification of the scanning electron microscope, for both the coated and untreated samples.

\section{Acknowledgement}

This research was made possible through research funds provided by the National Center for Education and Research in Corrosion and Materials Processing [NCERCAMP (Akron, Ohio)] Program Monitor: Ms. Susan Louscher as a sub grant to a Department of Defense research funding made available to NCECAMP. This material is based on research sponsored by the U.S Air Force Academy under agreement number FAJ00013-20023. The U.S government is authorized to reproduce and distribute reprints for government purposes notwithstanding any copyright solution thereon.

\section{References}

1. Aruna ST, William Grips VK, Rajam KS. Ni-based electrodeposited composite coating exhibiting improved microhardness, corrosion and wear resistance properties. Journal of Alloys and Compounds. 2009;468(1-2):546-552.

2. Conde A. Navas C, Cristóbal AB, Housden J, de Damborenea J
Characterisation of corrosion and wear behaviour of nanoscaled e-beam PVD CrN coatings. Surface and Coatings Technology. 2006;201(6):2690-2695.

3. Jacek J, Khannab AS, Jacek K, Mishrad DS, Racoltae P, Piran S, et al. Effect of chromium nitride coating on the corrosion and wear resistance of stainless steel. Applied Surface Science. 2000;156(1-4):47-64.

4. Duplex and super duplex steels. The significance of intermetallic and nitride precipitates in duplex and superduplex stainless steels. The Welding Institute. November 2002.

5. Herenu S, Moscatob MG, Alvarezb I, Armasb AF. The influence of chromium nitrides precipitation on the fatigue behavior of duplex stainless steels. XVII International Colloquium on Mechanical Fatigue of Metals (ICMFM17). Procedia Engineering. 2014;74:179 - 182.

6. Kochmański P, Nowacki J. Activated gas nitriding of 17-4 PH stainless steel. Surface and Coatings Technology. 2006;200(22-23):6558-6562.

7. Monika C, Marcin K, Witold R, Klas E, Wiesław R, Andrzej K. Parylene coatings on stainless steel 316L surface for medical applications mechanical and protective properties. Mater Sci Eng C. 2012;32(1):3135.

8. Wei-Shyan Lee, Tzay-Tian Su. Mechanical properties and microstructural features of AISI 4340 high-strength alloy steel under quenched and tempered conditions. Journal of Materials Processing Technology. 1999;87(1-3):198-206.

9. Tiwari SK, Jhuma A, Singh T, Raghuvir S. Preparation and characterization of sol-gel derived yttria doped zirconia coatings on AISI 316L. Thin Solid Films. 2009;517(16):4502-4508.

10. ASTM E8-2013: Standard Test method for Tension Testing of Metallic Materials. American Society for Testing and Materials. ASTM. Race Street. Philadelphia. PA. 2013.

11. Kwon H, Cha JC, Kim KC. The effect of grain size on fracture behaviour in tempered martensite embrittlement for AISI 4340 steel. Materials Science and Engineering. 1988;100:121-128.

12. Manigandan K. A study of microstructure, quasi-static response fatigue, deformation and fracture behavior of high strength alloy steels. Doctor of Philosophy Thesis. The University of Akron. Akron. Ohio. USA. December 2014.

13. G. E. Dieter. Mechanical Metallurgy. 3rd ed. McGraw Hill Publishers; 2006.

14. Pascover JS, Malas SJ. Structure and Properties of Ultra-High Strength Steels. ASTM STP 370. ASTM. Philadelphia, USA. 1965;370-389. 